\title{
Nonimmunity against hepatitis B virus infection in patients newly diagnosed with inflammatory bowel disease
}

\author{
Seong Jae Yeo ${ }^{1}$, Hyun Seok Lee ${ }^{1}$, Byung Ik Jang ${ }^{2}$, Eun Soo Kim ${ }^{1}$, Seong Woo Jeon ${ }^{1}$, Sung Kook Kim ${ }^{1}$ \\ Kyeong Ok Kim², Yoo Jin Lee ${ }^{3}$, Hyun Jik Lee ${ }^{3}$, Kyung Sik Park ${ }^{3}$, Yun Jin Jung ${ }^{4}$, Eun Young Kim \\ Chang Heon Yang ${ }^{6}$, Crohn's and Colitis Association in Daegu-Gyeongbuk (CCAiD) \\ ${ }^{1}$ Department of Internal Medicine, Kyungpook National University Hospital, School of Medicine, Kyungpook National University, Daegu, \\ ${ }^{2}$ Department of Internal Medicine, Yeungnam University College of Medicine, Daegu, ${ }^{3}$ Department of Internal Medicine, Keimyung University \\ School of Medicine, Daegu, ${ }^{4}$ Department of Internal Medicine, Daegu Fatima Hospital, Daegu, ${ }^{5}$ Department of Internal Medicine, Catholic \\ University of Daegu School of Medicine, Daegu, ${ }^{6}$ Department of Internal Medicine, Dongguk University School of Medicine, Gyeongju, Korea
}

Background/Aims: This study aimed to elucidate the prevalence of hepatitis B virus (HBV) serologic markers in Korean patients newly diagnosed with, but not yet treated for inflammatory bowel disease (IBD). Methods: We prospectively enrolled 210 patients newly diagnosed with IBD (109 with ulcerative colitis and 101 with Crohn's disease). Hepatitis B surface antigen (HBsAg), hepatitis B surface antibody (anti-HBs), and hepatitis B core antibody (anti-HBc) levels were measured and compared with those of 1,100 sex- and age-matched controls. Results: The prevalence of chronic HBV infection (positive HBsAg, positive anti-HBc, and negative anti-HBs results) and past infection (negative HBsAg, positive anti-HBc, and positive or negative anti-HBs results) were not significantly different between the patients and controls (chronic HBV infection: IBD, 3.8\% vs. control, $4.9 \%, P=0.596$; past infection: IBD, $26.2 \%$ vs. control, $28.8 \%, P=0.625)$. The patients with IBD aged $<20$ years were at a higher susceptibility risk (nonimmune) for HBV infection than the controls (IBD, $41.5 \%$ vs. control, $22.4 \% ; P=0.018$ ). In the multivariate analysis, an age of $<20$ years $(P=0.024)$ and symptom duration of $\geq 12$ months before diagnosis $(P=0.027)$ were identified as independent risk factors for nonimmunity against HBV infection. Conclusions: The patients newly diagnosed with IBD were susceptible to HBV infection. The frequency of nonimmunity was high, especially in the patients aged <20 years and those with a longer duration of symptoms before diagnosis. Therefore, it is necessary to screen for HBV serologic markers and generate a detailed vaccination plan for patients newly diagnosed with IBD. (Intest Res 2018;16:400-408)

Key Words: Inflammatory bowel disease; Colitis, ulcerative; Crohn disease; Hepatitis B virus; Vaccination

\section{INTRODUCTION}

Worldwide, approximately 400 million individuals have been infected with HBV; HBV infection remains the most

Received November 6, 2017. Revised January 15, 2018.

Accepted January 16, 2018. Published online March 6, 2018

Correspondence to Hyun Seok Lee, Department of Internal Medicine,

Kyungpook National University Hospital, School of Medicine, Kyungpook

National University, 807 Hoguk-ro, Buk-gu, Daegu 41404, Korea.

Tel: +82-53-200-2603, Fax:+82-53-200-2027,E-mail: Ihsworld@nate.com

Co-Correspondence to Byung Ik Jang, Department of Internal Medicine,

Yeungnam University Medical Center, Yeungnam University College of

Medicine, 170 Hyeonchung-ro, Nam-gu, Daegu 42415, Korea. Tel: +82-53-

620-3831, Fax: +82-53-654-8386,E-mail: jbi@med.yu.ac.kr common cause of liver cirrhosis and hepatocellular carcinoma. ${ }^{1}$ Korea is known as an HBV infection-endemic area, and before the 1980 s, its prevalence was $\sim 8 \%{ }^{2}$ Since the start of the neonatal vaccination project in 1995 , the prevalence of HBV infection has dramatically decreased; recently, the prevalence in school-aged children is less than $1 \% .^{2}$ In contrast, the current number of patients with IBD in Korea is increasing significantly. ${ }^{3}$

There has been a controversy over the prevalence of HBV infection in patients with IBD, and some recent studies have shown that there is no significant difference when it is compared with that of the general population. ${ }^{4-6}$ Additionally, there are some reports that even if patients with adolescent-

\footnotetext{
๑ Copyright 2018. Korean Association for the Study of Intestinal Diseases. All rights reserved.

This is an Open Access article distributed under the terms of the Creative Commons Attribution Non-Commercial License (http://creativecommons.org/licenses/by-nc/4.0)

which permits unrestricted non-commercial use, distribution, and reproduction in any medium, provided the original work is properly cited.
} 
or adult-onset IBD were inoculated with the HBV vaccine when they were toddlers, their antibody titers were still low during adulthood because of the effect of immunosuppressants. ${ }^{7-10}$ However, these studies have shown that low antibody titers are caused by external factors, such as drugs; IBD itself was not mentioned as a factor.

Therefore, in this study, we compared the prevalence among patients who were newly diagnosed with IBD, those who had never been treated for the disease, and the general population. Further, when these patients were diagnosed with IBD, we measured their HBV antibody levels that resulted from the inoculation with the HBV vaccine when they were toddlers.

\section{METHODS}

\section{Study Design}

We prospectively enrolled patients with IBD using data from the Crohn's and Colitis Association in the Daegu-Gyeongbuk registry between March 2014 and October 2015. We analyzed patients newly diagnosed with IBD; those not screened for HBV were excluded. All diagnoses of IBD were made on the basis of a detailed clinical history, close physical examination findings, laboratory data, and a combination of radiologic, endoscopic, and histological findings. At the time of diagnosis, a blood sample was collected from each patient for the evaluation of HBV infection markers. The study was approved by the ethics committee of the institutional review boards of the 7 tertiary referral medical centers conducting the research, and informed consent was obtained from each patient.

\section{Patients and Viral Serologic Markers}

From March 2014 to October 2015, 210 patients newly diagnosed with IBD (101 with CD and 109 with UC) were enrolled in our study. HBsAg, anti-HBc, and anti-HBs levels were evaluated in all 210 patients. Demographic and clinical characteristics, including age at the time of IBD diagnosis, symptom duration before diagnosis, and sex, were documented for the examination of possible risk factors for nonimmunity (defined as anti-HBs level of $<10 \mathrm{mIU} / \mathrm{mL}$, anti-HBc negativity, and HBsAg negativity) against HBV infection. A total of 1,100 individuals who visited the Health Medical Examination Center of Keimyung University Hospital, Daegu, Korea from March 2014 to September 2015 for a routine health examination were included as healthy controls. The number of the sex- and age-matched controls was five times higher than that of the patients newly diagnosed with IBD. All patients completed a questionnaire regarding their medical and personal history; those diagnosed with IBD were excluded. Because the prevalence of HBV infection in younger adults is dramatically decreasing because of the implementation of the HBV neonatal vaccination strategy in 1995, ${ }^{11}$ our study divided the patients with IBD into 3 subgroups, according to age at the time of diagnosis: $<20,20-44$, and $\geq 45$ years. We then compared the prevalence of HBV infection serologic markers (HBsAg, anti-HBs, and anti-HBc) by subgroup. These markers were analyzed using a chemiluminescent immunoassay method (ADVIA Centaur, Siemens Health Care Diagnostics Inc., Tarrytown, NY, USA).

\section{Definitions}

Past and present HBV infections were defined on the basis of the terminology applied by the National Institutes of Health's conferences on the management of hepatitis B. ${ }^{12}$ Past HBV infection was defined as anti-HBc positivity with or without anti-HBs. Present HBV infection was defined as the existence of HBsAg. Effective vaccination was defined as an anti-HBs level of $\geq 10 \mathrm{mIU} / \mathrm{mL}$, HBsAg negativity, and anti-HBc negativity. Nonimmunity was defined as an antiHBs level of $<10 \mathrm{mIU} / \mathrm{mL}$, HBsAg negativity, and anti-HBc negativity. ${ }^{13}$

\section{Statistical Analysis}

Categorical variables were analyzed using Fisher exact test or the chi-square test. Continuous variables were examined using Student $t$-test. The results were expressed as means with SDs or medians with interquartile ranges (IQRs). A multivariate analysis of the independent risk factors for nonimmunity was performed using binary logistic regression after the identification of appropriate risk factors that presented significant correlations $(P<0.1)$ in the univariate analysis. Two-tailed $P$-values of $<0.05$ were considered statistically significant. The statistical analysis was performed using SPSS version 20.0 (IBM Corp., Armonk, NY, USA).

\section{RESULTS}

\section{Demographic and Clinical Characteristics of the Patients Newly Diagnosed with IBD}

Patient age at the time of CD diagnosis was significantly lower than that at the time of UC diagnosis $(26.6 \pm 12.5$ years 
vs. $42.7 \pm 18.0$ years, $P<0.001)$. The symptom duration before diagnosis was longer in the patients with $\mathrm{CD}$ than in those with UC $(17.4 \pm 32.6$ months vs. $10.6 \pm 24.7$ months, $P<0.001)$. The clinical characteristics of the patients with IBD according to Montreal classification are shown in Table 1.

Table 1. Clinical Characteristics of the Patients with IBD

\begin{tabular}{lccc}
\hline \multicolumn{1}{c}{ Characteristics } & $\begin{array}{c}\text { CD } \\
(\mathbf{n = 1 0 1 )})\end{array}$ & $\begin{array}{c}\text { UC } \\
(\mathbf{n}=109)\end{array}$ & P-value \\
\hline Age at diagnosis (yr) & $26.6 \pm 12.5$ & $42.7 \pm 18.0$ & $<0.001$ \\
Symptom duration before diagnosis (mo) & $17.4 \pm 32.6$ & $10.6 \pm 24.7$ & $<0.001$ \\
Male sex & $74(73.2)$ & $59(54.1)$ & 0.007 \\
CD location & & & \\
L1 (terminal ileum) & $28(27.7)$ & \\
L2 (colon) & $35(34.7)$ & \\
L3 (ileocolonic) & $38(37.2)$ & \\
L4 (upper Gl) & $3(2.9)$ & \\
CD behavior & & \\
B1 (inflammatory) & $68(67.3)$ & \\
B2 (stricturing) & $18(17.8)$ & \\
B3 (penetrating) & $15(14.9)$ & \\
Perianal disease & $21(20.8)$ & \\
UC extent & & & \\
E1 (proctitis) & & \\
E2 (left-sided) & & \\
E3 (extensive) & & \\
\hline
\end{tabular}

Values are presented as mean \pm SD or as number (\%).

$\mathrm{Gl}$, gastrointestinal.

\section{Proportion of the HBV Infection Statuses between the Patients and Controls}

The proportion of the HBV infection statuses between the patients and controls is shown in Table 2. No significant difference in the prevalence of chronic HBV infection (positive HBsAg, positive anti-HBc, and negative anti-HBs results) was noted between the patients and controls (IBD, 3.9\% [CD, $1.0 \%$; UC, $6.5 \%]$ vs. control, $4.8 \% ; P=0.596$ ). The prevalence of past infection (negative HBsAg, positive anti-HBc, and positive or negative anti-HBs results) was not significantly different between the patients and controls (IBD, 25.2\% [CD, $25.7 \%$; UC, $24.7 \%$ ] vs. control, $27.7 \%, P=0.625)$. Effective vac-

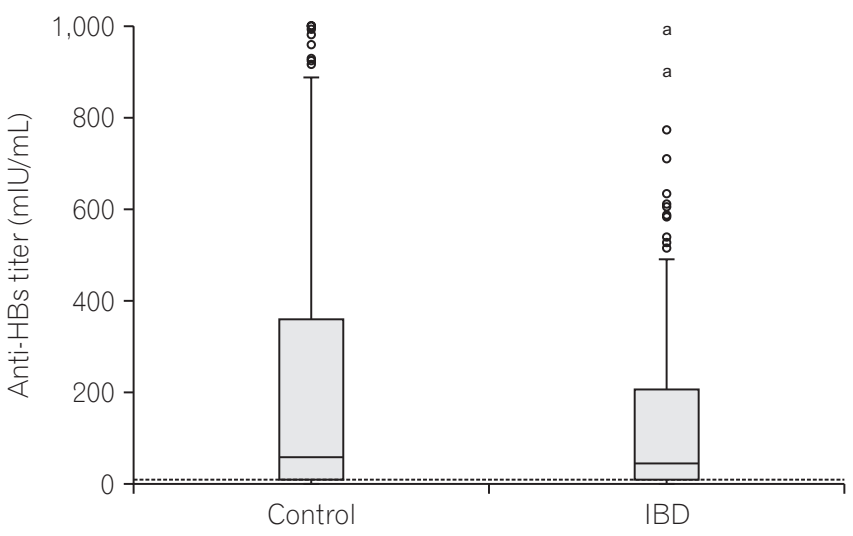

Fig. 1. Quantitative anti-HBs titer of the patients with IBD and controls. The median titer of the patients with IBD was $44.20 \mathrm{mIU} / \mathrm{mL}$ (interquartile range $[I O R], 11.19-209.51 \mathrm{mlU} / \mathrm{mL})$, and that of the controls was $59.00 \mathrm{mlU} / \mathrm{mL}(\mathrm{IQR}, 8.00-360.83 \mathrm{mlU} / \mathrm{mL})(P=0.031)$. The horizontal dot bar indicates the mean cutoff value of $10 \mathrm{mIU} / \mathrm{mL}$. The IBD group mean very high level of titers.

Table 2. Proportion of the HBV Infection Statuses between the Patients and Controls

\begin{tabular}{|c|c|c|c|c|c|}
\hline & $C D(n=101)$ & UC $(n=109)$ & IBD $(n=210)$ & Control $(n=1,100)$ & $P$-value \\
\hline Chronic HBV infection $^{b}$ & 1.0 & 6.5 & 3.9 & 4.8 & 0.596 \\
\hline Past infection ${ }^{c}$ & 25.7 & 24.7 & 25.2 & 27.7 & 0.625 \\
\hline Effective vaccination $^{d}$ & 38.6 & 38.5 & 38.5 & 48.0 & 0.013 \\
\hline Nonimmunity ${ }^{e}$ & 34.7 & 30.3 & 32.4 & 19.5 & $<0.001$ \\
\hline
\end{tabular}

Values are presented as percentages.

${ }^{\mathrm{a}} \mathrm{IBD}$ vs. control.

${ }^{6}$ Chronic HBV was defined as HBsAg positivity, anti-HBc positivity, and anti-HBs negativity. ${ }^{13} \mathrm{CD}$ vs. UC, $P=0.067 ; \mathrm{CD}$ vs. control, $P=0.080 ; \mathrm{UC}$ vs. control, $P=0.489$.

${ }^{\mathrm{C}}$ Past infection was defined as HBsAg negativity, anti-HBc positivity, and anti-HBs negativity or positivity. ${ }^{13} \mathrm{CD}$ vs. UC, $P=0.885 ; \mathrm{CD}$ vs. Control, $P=1.000$; UC vs. control, $P=0.768$

${ }^{d}$ Effective vaccination was defined as HBsAg negativity, anti-HBc negativity, and anti-HBs level of $\geq 10 \mathrm{mlU} / \mathrm{mL}$. ${ }^{13} \mathrm{CD}$ vs. UC, $P=1.000$; CD vs. control, $P=0.029$; UC vs. control, $P=0.044$.

${ }^{e}$ Nonimmunity was defined as HBsAg negativity, anti-HBc negativity, and anti-HBs level of $<10 \mathrm{mlU} / \mathrm{mL}{ }^{13} \mathrm{CD}$ vs. UC, $P=0.556$; $\mathrm{CD}$ vs. control, $P=0.001$; UC vs. control, $P=0.020$. 
cination (negative HBsAg and negative anti-HBc results and anti-HBs level of $\geq 10 \mathrm{mIU} / \mathrm{mL}$ ) was identified in $38.5 \%$ of the patients with IBD (CD, 38.6\%; UC, 38.5\%), which was significantly lower than that of the control group $(48.0 \%, P=0.013)$. However, there was no statistically significant intergroup difference regarding the effective vaccination rates when
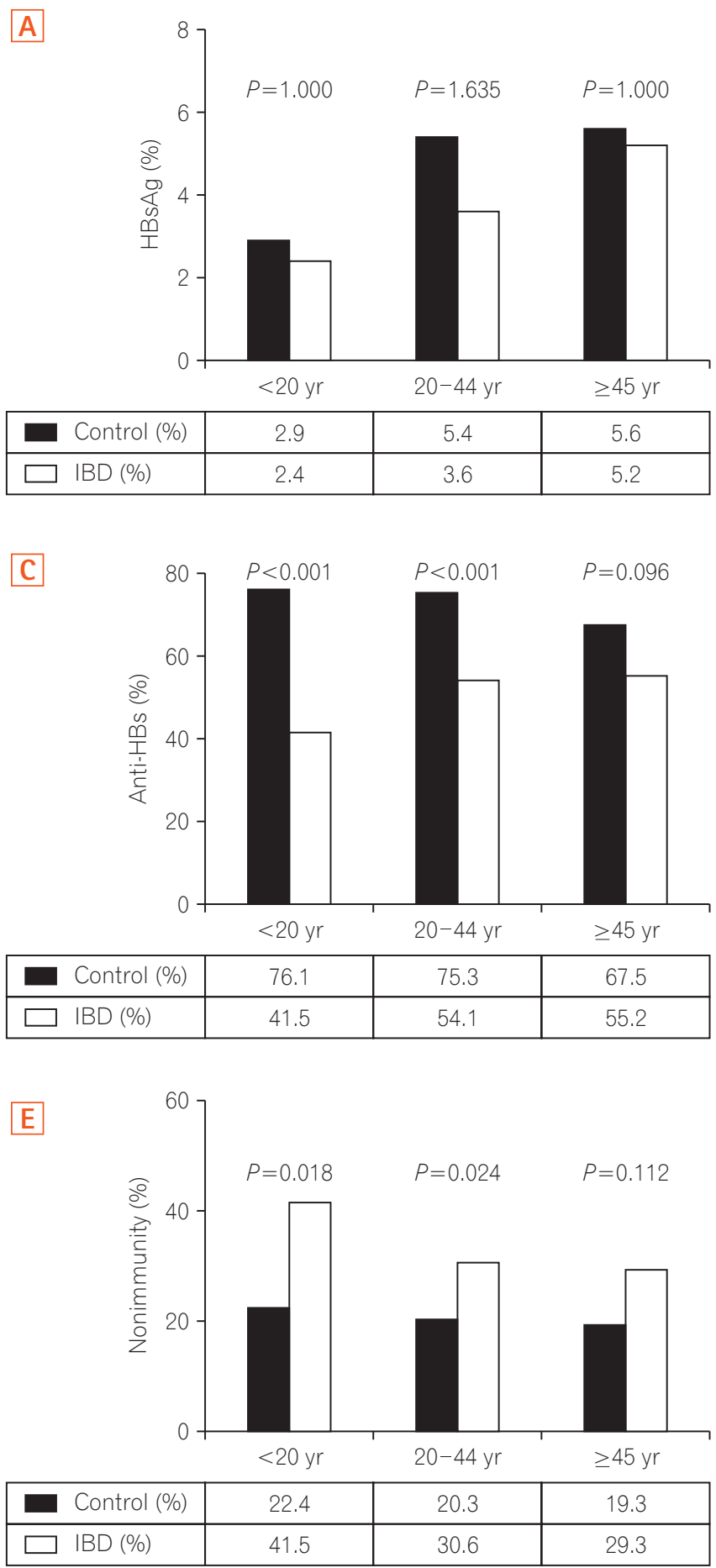

the patients were divided into those with UC and those with CD (Table 2). Nonimmunity against HBV infection (negative HBsAg and negative anti-HBc results and anti-HBs level of $<10 \mathrm{mIU} / \mathrm{mL}$ ) was detected in $32.4 \%$ of the patients (CD, $34.7 \%$; UC, $30.3 \%$ ) compared with that in $19.5 \%$ of the controls $(P<0.001)$. The quantitative anti-HBs titer of the patients
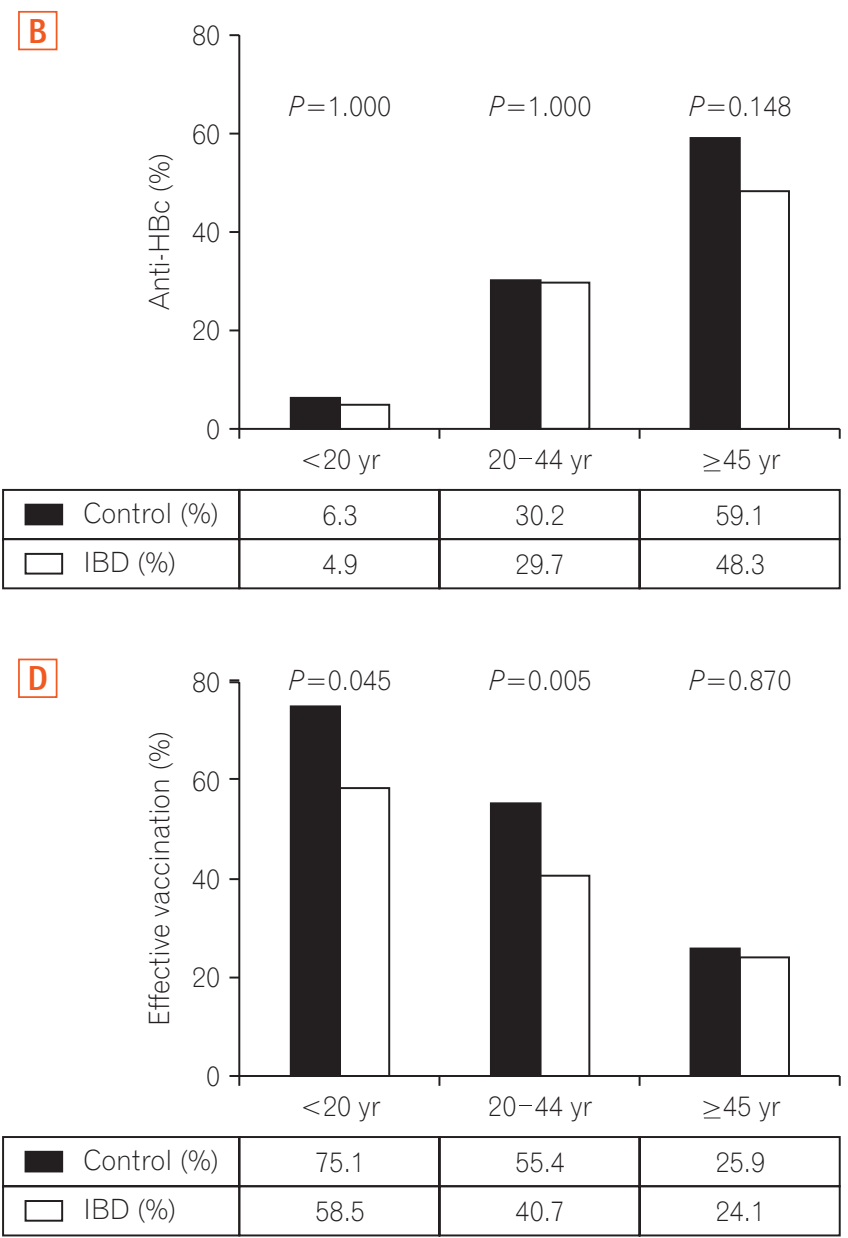

Fig. 2. Prevalence of $H B V$ infection serologic markers by age at the time of diagnosis. (A) HBsAg; (B) anti-HBc; (C) anti-HBs; (D) effective vaccination; (E) nonimmunity. 
with IBD and controls is shown in Fig. 1. The median titer of the patients with IBD was $44.20 \mathrm{mIU} / \mathrm{mL}$ (IQR, 11.19-209.51 $\mathrm{mIU} / \mathrm{mL}$ ), and that of the controls was $59.00 \mathrm{mIU} / \mathrm{mL}$ (IQR, $8.00-360.83 \mathrm{mIU} / \mathrm{mL})(P=0.031)$. Further, the cutoff value was $10 \mathrm{mIU} / \mathrm{mL}$ as indicated by the horizontal dot bar in Fig. 1 .

\section{Prevalence of HBV Infection Serologic Markers by Age at the Time of Diagnosis}

When the patients were divided into the 3 age-based subgroups $(<20,20-44$, and $\geq 45$ years $)$, the prevalence of HBsAg positivity and anti-HBc positivity did not differ between the patients and controls regardless of age (Fig. 2A and B). However, anti-HBs positivity was noted significantly less frequently in the patients newly diagnosed with IBD than in the controls in the $<20$ years (IBD, $41.5 \%$; control, $76.1 \%$; $P<0.001$ ) and $20-44$ years (IBD, $54.1 \%$; control, $75.3 \%$, $P<0.001)$ subgroups, while no marked difference was seen in the $\geq 45$ years subgroup (Fig. 2 C). Effective vaccination was significantly less common in the patients newly diagnosed with IBD than in the controls in the $<20$ years (IBD, 58.5\%; control, $75.1 \% ; P=0.045$ ) and $20-44$ years subgroups (IBD, 40.7\%; control, $55.4 \%$; $P=0.005$ ); conversely, there was no meaningful difference between the patients and controls in the $\geq 45$ years (IBD, $24.1 \%$; control, $25.9 \%$; $P=0.870$ ) subgroup (Fig. 2D). Nonimmunity against HBV infection was more frequent in the patients newly diagnosed with IBD than in the controls in the $<20$ years (IBD, $41.5 \%$; control, $22.4 \% ; P=0.018$ ) and $20-44$ years (IBD, $30.6 \%$; control, $20.3 \%$; $P=0.024$ ) subgroups; there was no statistically significant difference between the patients newly diagnosed with IBD and controls in the $\geq 45$ years subgroup (IBD, $29.3 \%$; control, $19.3 \% ; P=0.112$ ) (Fig. 2E).

\section{Risk Factors for Nonimmunity against HBV Infection in the Patients Newly Diagnosed with IBD}

The univariate and multivariate analyses findings are shown in Table 3 . Nonimmunity was significantly correlated with the age of $<20$ years at the time of diagnosis $(P=0.016)$ and symptom duration of $\geq 12$ months before diagnosis $(P=0.035)$. Age of $<20$ years (OR, 2.589; 95\% CI, 1.134-5.909; $P=0.024)$ and symptom duration of $\geq 12$ months before diagnosis (OR, 2.077; 95\% CI, 1.085-3.977; $P=0.027$ ) were the independent risk factors for nonimmunity against HBV infection in the multivariate analysis. However, sex and IBD type were not correlated with nonimmunity.

\section{DISCUSSION}

To our knowledge, the current study is the first to assess the prevalence of $\mathrm{HBV}$ infection serologic markers and im-

Table 3. Univariate and Multivariate Analyses of the Risk Factors for Nonimmunity (Anti-HBs Level of $<10 \mathrm{mIU} / \mathrm{mL}$ and Anti-HBc and HBsAg Negativity) to HBV Infection in the Patients with IBD

\begin{tabular}{|c|c|c|c|c|c|}
\hline \multirow{2}{*}{ Characteristics } & \multicolumn{3}{|c|}{ Univariate analysis } & \multicolumn{2}{|c|}{ Multivariate analysis } \\
\hline & Nonimmunity $(n=90)^{a}$ & Immune or exposed $(n=120)^{b}$ & $P$-value & OR $(95 \% \mathrm{Cl})$ & $P$-value \\
\hline Age at diagnosis (yr) & & & 0.016 & & \\
\hline$<20$ & $24(26.7)$ & $17(14.2)$ & & $2.589(1.134-5.909)$ & 0.024 \\
\hline $20-44$ & $45(50.0)$ & $63(52.5)$ & & $1.280(0.603-2.308)$ & 0.630 \\
\hline$\geq 45$ & $21(23.3)$ & 40 (33.3) & & 1 & \\
\hline Sex & & & 0.785 & & \\
\hline Male & $56(62.2)$ & $76(63.3)$ & & & \\
\hline Female & $34(37.8)$ & $44(36.7)$ & & & \\
\hline Symptom duration (mo) & & & 0.035 & & \\
\hline$\geq 12$ & $31(34.4)$ & $24(20.0)$ & & $2.077(1.085-3.977)$ & 0.027 \\
\hline$<12$ & $59(65.6)$ & $96(80.0)$ & & 1 & \\
\hline Disease & & & 0.372 & & \\
\hline$C D$ & $47(52.2)$ & $54(45.0)$ & & & \\
\hline UC & $43(47.8)$ & $66(55.0)$ & & & \\
\hline
\end{tabular}

Values are presented as number (\%).

${ }^{a}$ Anti-HBs level of $<10 \mathrm{mlU} / \mathrm{mL}$ and anti-HBc and $\mathrm{HBsAg}$ negativity.

${ }^{b}$ Anti-HBs level of $\geq 10 \mathrm{mlU} / \mathrm{mL}$ or anti-HBc positivity. 
mune status against $\mathrm{HBV}$ infection in patients newly diagnosed with IBD; we also compared patients with sex- and age-matched healthy controls. Two studies in Italy and Brazil reported that the HBsAg-positivity rates were significantly higher in patients with IBD than in the general population. ${ }^{14,15}$ However, other studies from France, Italy, Spain, and Korea reported that the HBsAg-positivity rates in patients with IBD were not significantly different from those in controls. ${ }^{4,5,16,17}$

The prevalence of HBV infection markers in patients newly diagnosed with IBD in our study was considerably higher than that reported from Western studies. For example, a multicenter study of patients with IBD in Spain presented a $0.6 \%$ HBsAg-positivity rate and a $7.1 \%$ anti-HBc-positivity rate. ${ }^{4}$ Our study reported a $3.8 \%$ HBsAg-positivity rate and a $30.0 \%$ anti-HBc-positivity rate in Korean patients newly diagnosed with IBD, which were higher than those reported by the previous study. ${ }^{4}$ Other Korean IBD studies presented HBsAg-positivity rates of $3.7 \%$ and $4.1 \%$, similar to those of this study ${ }^{16,18}$ Our study demonstrated no significant difference in the HBsAg-positivity rate between the patients newly diagnosed with IBD and the general population of Korea, an HBV infection-endemic country. This result supported the data from recent studies conducted in Western countries, suggesting that IBD is no longer a risk factor for HBV infection. $^{4-6}$

A comparable prevalence of HBV infection serologic markers in patients with IBD in Western countries has been reported. ${ }^{4,5}$ In our study, the positivity rate of anti-HBc, an indicator of previous HBV exposure, was similar with that of a previous study. ${ }^{19}$ When the patients newly diagnosed with IBD were divided into 3 subgroups by their age at the time of diagnosis, the anti-HBc-positivity rate increased with age. However, there was no significant difference between the patients with IBD and the controls, indicating that HBV exposure depends highly on the patient's age at the time of diagnosis. An analysis of $\mathrm{HBV}$ infection markers in Korean individuals showed that the anti-HBc-positivity rate decreased meaningfully with a younger age ${ }^{19}$ a pattern similar to that of our data. Our study findings were influenced by the nationwide prophylactic HBV vaccination of neonates implemented in Korea in 1995. A Japanese study ${ }^{20}$ compared viral markers of hepatitis B in patients with rheumatoid arthritis (RA) and systemic lupus erythematosus (SLE). The anti-HBc-positivity rate in RA was $\sim 25.6 \%$, and that in SLE was $\sim 14.2 \%$. In contrast to the $12.2 \%$ anti-HBc-positivity rate of the control group in other studies in Japan, ${ }^{21}$ there was no significant difference in SLE; however, that in RA had a dif- ference. They reported that the reason is that patients with RA are relatively older than patients with SLE. Our study also showed that the anti-HBc-positivity rate increases with age.

Our study found that the vaccination effectiveness in the patients newly diagnosed with IBD was significantly lesser than that in the controls. Many studies have presented that immunosuppressant use reduces $\mathrm{HBV}$ vaccination efficacy. ${ }^{7-10}$ However, the patients in this study were newly diagnosed with and not yet treated for IBD, and the vaccination effectiveness results were similar to those in another study. ${ }^{18}$ He et al. ${ }^{22}$ opposed that HBV infection in patients with IBD could worsen when treated with immunosuppressants; their finding was concordant with those of this study. We also found that the vaccination effectiveness rate was significantly lower in the subgroup of patients newly diagnosed with IBD aged $<20$ years than in the age-matched controls (IBD, $58.5 \%$ vs. control, $75.1 \%, P=0.045$ ). We did not compare the vaccination rates between the patients and controls; however, we can assume that the vaccination rate of the $<20$-year subgroup would be higher than that of the other subgroups because of the nationwide vaccination strategy. Therefore, it appears that the lower vaccination effectiveness rate in the patients newly diagnosed with IBD was because of reasons other than the vaccination rate and use of immunosuppressants. One possible explanation for this might be a confused immune response. Cellular immune responses initiated by Type 1 helper T cells, cytokines, and regulatory T (Treg) cells effectively protect against and downregulate inflammation in human studies and animal models of $\mathrm{CD}{ }^{23} \mathrm{HBV}$ infection is also thought to cause an unusual cell-mediated immune response, and it has been proven that Treg cells are an important prognostic factor of $\mathrm{HBV}$ infection. ${ }^{24}$ However, these hypotheses should be investigated in future research studies; nevertheless, Treg cells seem to affect both HBV infection and IBD; thus, HBV infection is likely to influence the pathogenesis of IBD and vice versa. Therefore, the aberrant immune response in patients with IBD can cause a disturbance in the $\mathrm{HBV}$ vaccine response. ${ }^{25,26}$

One of the significant findings of our study was that nonimmunity to HBV infection makes patients newly diagnosed with IBD significantly susceptible to such an infection. The nonimmunity rate was quite prominent in the subgroup of patients newly diagnosed with IBD who were aged $<20$ years compared with that in the controls (IBD, 41.5\%; controls, $22.4 \% ; P=0.018$ ) and was statistically significant in the patients with IBD aged 20-44 years compared with that in the controls (IBD, 30.6\%; control, 20.3\%; $P=0.024$ ). In the multivariate analysis, age of $<20$ years and symptom dura- 
tion of $\geq 12$ months before diagnosis were identified as the independent risk factors for nonimmunity. Previous studies have reported that chronic liver disease, chronic kidney disease, and human immunodeficiency virus infection reduce the efficacy of $\mathrm{HBV}$ vaccination. ${ }^{27-29}$ However, no other study mentioned IBD as a risk factor for HBV infection. To our knowledge, this is the first study to analyze the symptom duration as a risk factor for $\mathrm{HBV}$ infection. These results may explain the aberrant immune response seen in patients with $\mathrm{IBD}^{25,26}$

The current study has some limitations. First, we did not check the HBV DNA levels of the patients with negative HBsAg and positive anti-HBc results. Thus, we did not measure the occult HBV levels. Patients with positive anti-HBc results are at a risk of occult HBV infection, which is a reactivation indicator particularly in those treated with chemotherapy or immunosuppressants. ${ }^{30-32}$ In fact, immunosuppressant use is the main cause of $\mathrm{HBV}$ infection reactivation in patients with IBD. ${ }^{30,31}$ Many patients with IBD use long-term immunosuppressants, and their immune status is usually low, increasing their susceptibility to conditions, such as tuberculosis, cytomegalovirus colitis, and HBV infection reactivation. Therefore, occult HBV infection reactivation is an important potential outcome to consider in these patients, especially in Korea, an HBV infection-endemic country. ${ }^{32-37}$ Therefore, further studies that would explore occult HBV infection in patients with IBD need to be conducted. However, at approximately $0.016 \%$, the prevalence of occult HBV infection in Korea is very low. ${ }^{38}$ Second, our study was performed in Daegu-Gyeongbuk, a southeastern local area of Korea; however, its prevalence of $\mathrm{HBV}$ infection is similar to the mean rate in the country (overall country, 4.0\%; Daegu, 4.2\%; Gyeongbuk, 3.9\%). ${ }^{39}$ Our study compared the patient group with a control group, which had a five times higher number of patients, and identified a prevalence rate similar to that of a nationwide study.

In conclusion, the current study is the first to compare the prevalence of HBV infection serologic markers between patients newly diagnosed with IBD and controls, and we found that the prevalence of HBsAg positivity in the patients newly diagnosed with IBD was not significantly different from that of the general population of Korea. The vaccination efficacy was markedly lesser in the patients with IBD aged $<20$ years at the time of diagnosis than in the controls. Of note, age of $<20$ years and symptom duration of $\geq 12$ months before diagnosis were the independent risk factors for nonimmunity. Thus, the investigation of the HBV vaccination status of young patients and those with a longer symptom duration at the time of IBD diagnosis is important. Finally, the continued enforcement of a detailed national vaccination plan in Korea, an HBV infection-endemic country, is needed.

\section{FINANCIAL SUPPORT}

The authors received no financial support for the research, authorship, and/or publication of this article.

\section{CONFLICT OF INTEREST}

No potential conflict of interest relevant to this article was reported.

\section{AUTHOR CONTRIBUTION}

Seong Jae Yeo contributed to analysis and interpretation of data, and writing and revising the manuscript. Hyun Seok Lee contributed to concept and design of the study and reviewing the manuscript. Byung Ik Jang contributed reviewing and intellectual content of the article. All authors contributed to acquisition of data and approved the final version of the manuscript for submission.

\section{REFERENCES}

1. Lee WM. Hepatitis B virus infection. N Engl J Med 1997;337:1733-1745.

2. Kwon SY, Lee CH. Epidemiology and prevention of hepatitis B virus infection. Korean J Hepatol 2011;17:87-95.

3. Yang SK, Yun S, Kim JH, et al. Epidemiology of inflammatory bowel disease in the Songpa-Kangdong district, Seoul, Korea, 1986-2005: a KASID study. Inflamm Bowel Dis 2008;14:542549.

4. Loras C, Saro C, Gonzalez-Huix F, et al. Prevalence and factors related to hepatitis $\mathrm{B}$ and $\mathrm{C}$ in inflammatory bowel disease patients in Spain: a nationwide, multicenter study. Am J Gastroenterol 2009;104:57-63.

5. Chevaux JB, Nani A, Oussalah A, et al. Prevalence of hepatitis $\mathrm{B}$ and $\mathrm{C}$ and risk factors for nonvaccination in inflammatory bowel disease patients in Northeast France. Inflamm Bowel Dis 2010;16:916-924.

6. Harsh P, Gupta V, Kedia S, et al. Prevalence of hepatitis B, hepatitis $\mathrm{C}$ and human immunodeficiency viral infections in patients with inflammatory bowel disease in north India. Intest Res 2017;15:97-102. 
7. Altunöz ME, Senateş E, Yeşil A, Calhan T, Ovünç AO. Patients with inflammatory bowel disease have a lower response rate to $\mathrm{HBV}$ vaccination compared to controls. Dig Dis Sci 2012;57:1039-1044.

8. Vida Pérez L, Gómez Camacho F, García Sánchez V, et al. Adequate rate of response to hepatitis $B$ virus vaccination in patients with inflammatory bowel disease. Med Clin (Barc) 2009;132:331-335.

9. Melmed GY, Ippoliti AF, Papadakis KA, et al. Patients with inflammatory bowel disease are at risk for vaccine-preventable illnesses. Am J Gastroenterol 2006;101:1834-1840.

10. Wörns MA, Teufel A, Kanzler S, et al. Incidence of HAV and HBV infections and vaccination rates in patients with autoimmune liver diseases. Am J Gastroenterol 2008;103:138-146.

11. Lee KI, Park KS, Seo HJ, et al. Shifting in seroprevalence of HBsAg and anti-HCV during recent 10 years in adults resident in Daegu and Gyeongbuk province. Korean J Gastroenterol 2011;58:82-87.

12. Lok AS, McMahon BJ. Chronic hepatitis B. Hepatology 2007;45:507-539.

13. Moses J, Alkhouri N, Shannon A, et al. Hepatitis B immunity and response to booster vaccination in children with inflammatory bowel disease treated with infliximab. Am J Gastroenterol 2012;107:133-138.

14. Tolentino YF, Fogaca HS, Zaltman C, Ximenes LL, Coelho HS. Hepatitis B virus prevalence and transmission risk factors in inflammatory bowel disease patients at Clementino Fraga Filho University Hospital. World J Gastroenterol 2008;14:3201-3206.

15. Biancone L, Pavia M, Del Vecchio Blanco G, et al. Hepatitis B and $\mathrm{C}$ virus infection in Crohn's disease. Inflamm Bowel Dis 2001;7:287-294.

16. Park SH, Yang SK, Lim YS, et al. Clinical courses of chronic hepatitis B virus infection and inflammatory bowel disease in patients with both diseases. Inflamm Bowel Dis 2012;18:20042010.

17. Papa A, Felice C, Marzo M, et al. Prevalence and natural history of hepatitis B and C infections in a large population of IBD patients treated with anti-tumor necrosis factor-alpha agents. J Crohns Colitis 2013;7:113-119.

18. Kim ES, Cho KB, Park KS, et al. Prevalence of hepatitis-B viral markers in patients with inflammatory bowel disease in a hepatitis-B-endemic area: inadequate protective antibody levels in young patients. J Clin Gastroenterol 2014;48:553-558.

19. Song EY, Yun YM, Park MH, Seo DH. Prevalence of occult hepatitis B virus infection in a general adult population in Korea. Intervirology 2009;52:57-62.
20. Watanabe R, Ishii T, Kobayashi H, et al. Prevalence of hepatitis $B$ virus infection in patients with rheumatic diseases in Tohoku area: a retrospective multicenter survey. Tohoku J Exp Med 2014;233:129-133.

21. Marusawa H, Osaki Y, Kimura T, et al. High prevalence of antihepatitis B virus serological markers in patients with hepatitis C virus related chronic liver disease in Japan. Gut 1999;45:284288.

22. He Y, Xu P, Chen Y, et al. Prevalence and influences of hepatitis $B$ virus infection on inflammatory bowel disease: a retrospective study in southern China. Int J Clin Exp Med 2015;8:80788085.

23. Maul J, Loddenkemper C, Mundt P, et al. Peripheral and intestinal regulatory CD4+ CD25(high) T cells in inflammatory bowel disease. Gastroenterology 2005;128:1868-1878.

24. Aalaei-Andabili SH, Alavian SM. Regulatory T cells are the most important determinant factor of hepatitis B infection prognosis: a systematic review and meta-analysis. Vaccine 2012;30:55955602.

25. Jafarzadeh A, Shokri F. The antibody response to HBs antigen is regulated by coordinated Th1 and Th2 cytokine production in healthy neonates. Clin Exp Immunol 2003;131:451-456.

26. Pallone F, Monteleone G. Interleukin 12 and Th1 responses in inflammatory bowel disease. Gut 1998;43:735-736.

27. Filippelli M, Lionetti E, Gennaro A, et al. Hepatitis B vaccine by intradermal route in non responder patients: an update. World J Gastroenterol 2014;20:10383-10394.

28. Wolters B, Junge U, Dziuba S, Roggendorf M. Immunogenicity of combined hepatitis A and B vaccine in elderly persons. Vaccine 2003;21:3623-3628.

29. Averhoff F, Mahoney F, Coleman P, Schatz G, Hurwitz E, Margolis H. Immunogenicity of hepatitis B Vaccines: implications for persons at occupational risk of hepatitis B virus infection. Am J Prev Med 1998;15:1-8.

30. Madonia S, Orlando A, Scimeca D, Olivo M, Rossi F, Cottone M. Occult hepatitis B and infliximab-induced HBV reactivation. Inflamm Bowel Dis 2007;13:508-509.

31. Iannitto E, Minardi V, Calvaruso G, et al. Hepatitis B virus reactivation and alemtuzumab therapy. Eur J Haematol 2005;74:254258.

32. Law JK, Ho JK, Hoskins PJ, Erb SR, Steinbrecher UP, Yoshida EM. Fatal reactivation of hepatitis B post-chemotherapy for lymphoma in a hepatitis B surface antigen-negative, hepatitis B core antibody-positive patient: potential implications for future prophylaxis recommendations. Leuk Lymphoma 2005;46:10851089. 
33. Lee DS, Bang KB, Kim JY, et al. The prevalence and clinical characteristics of anemia in Korean patients with inflammatory bowel disease. Intest Res 2016;14:43-49.

34. Suzuki Y, Iida M, Ito H, Saida I, Hibi T. Efficacy and safety of two pH-dependent-release mesalamine doses in moderately active ulcerative colitis: a multicenter, randomized, double-blind, parallel-group study. Intest Res 2016;14:50-59.

35. Wu KC, Ran ZH, Gao X, et al. Adalimumab induction and maintenance therapy achieve clinical remission and response in Chinese patients with Crohn's disease. Intest Res 2016;14:152163.

36. Lee JW, Choi CH, Park JH, et al. Clinical features of active tuberculosis that developed during anti-tumor necrosis factor therapy in patients with inflammatory bowel disease. Intest Res 2016;14:146-151.
37. Nakase H, Keum B, Ye BD, Park SJ, Koo HS, Eun CS. Treatment of inflammatory bowel disease in Asia: the results of a multinational web-based survey in the 2(nd) Asian Organization of Crohn's and Colitis (AOCC) meeting in Seoul. Intest Res 2016;14:231-239.

38. Seo DH, Whang DH, Song EY, Kim HS, Park Q. Prevalence of antibodies to hepatitis B core antigen and occult hepatitis B virus infections in Korean blood donors. Transfusion 2011;51:18401846.

39. Lee BS, Cho YK, Jeong SH, et al. Nationwide seroepidemiology of hepatitis B virus infection in South Korea in 2009 emphasizes the coexistence of HBsAg and anti-HBs. J Med Virol 2013;85:1327-1333. 